\title{
A Set of Key Principles to Assess the Impact of Living Labs
}

\section{Anna Ståhlbröst}

\author{
Social Informatics \\ Luleå University of Technology \\ SE-971 87 Luleå, Sweden \\ Fax: +46920492849 \\ E-mail: anna.stahlbrost@ltu.se
}

\begin{abstract}
Among companies there is an ongoing shift from a product-based economy to a service economy, especially among companies who delivers digital services. The service sector is growing rapidly, which puts pressure on companies to keep up with their competitors. This is an often demanding process, especially for SMEs who do not have the resources to continuously develop their business. To support these SMEs' innovation processes, a concept called the Living Lab is starting to grow around Europe. These Living Labs strive to support companies' innovation processes by offering a neutral arena where different stakeholders can meet and codevelop innovations. However, the effects of Living Labs operations are to some extent unexplored and under-theorized. Therefore, the purpose of this paper is twofold: to propose a set of principles for conducting Living Lab research in an innovation context and to assess the impact of the Living Lab approach on the innovation process and its stakeholders by means of the proposed principles. This study shows that the Living Lab approach offers values in many different ways for several stakeholders.
\end{abstract}

Keywords: Living Lab, Open Innovation, Service Innovation, Key Principles, User Involvement

Biographical Notes: Anna Ståhlbröst is a researcher at Luleå University of Technology, Sweden. Her research is focused on Living Lab and open user driven innovation processes, with special interest in service innovation and users needs and motivators.

\section{Introduction}

There has been a huge shift from a product based economy to a service economy, especially with digital services (Williams et al., 2008). The economic future is expected to lie in services. According to Aas and Pedersen (2010), the service industry accounts for more than $70 \%$ of the GNP and employment in most developed countries. Hence, it is of vital importance for both service and manufacturing firms' success to create innovate services both in the short- and longterm (Bitner et al., 2008; Chesbrough, 2011; Shelton, 2009; van de Vrande et al., 2009). Innovative services can take many different forms: it can be to wrap a service around a product or reimagine a product as a service, such a software-as-a-service 
firms have done; it can also be to rescope the business area from products to services to feed future growth (Chesbrough, 2011). Service innovation consists of several components such as technology innovation, business model innovation, social-organisational innovation and demand innovation to create both incremental and radical innovations (Wooder \& Baker, 2012). At this stage, services offer an opportunity to sustain differentiation in a competitive environment that commoditizes products almost as fast as they emerge.

There are several reasons why the service innovation area is growing. Today, important drivers of competitive performance are globalization, rapid product and service innovation leadership, operational excellence, and customer intimacy. This puts high demands on companies that must handle structural barriers to agility and competitive performance (Rai \& Sambamurthy, 2006). The growth in services is also fuelled by firms using it as a defence against the standardization of products and as a strategy for productivity, growth, and retention.

However, creating innovative services that have market impact is not a straightforward process in which a given approach automatically leads to a desired output for the involved companies. For SMEs, the innovation process can be even harder to accomplish. Some SMEs might not have the resources, or all the needed competencies, to carry out the innovation activities necessary to make their business effective and efficient. To boost the innovation capacity for these SMEs, a concept called Living Labs is emerging rapidly around Europe. Living Labs strive to support the innovation process for all involved stakeholders, from manufacturers to end-users, with special attention to SMEs and a focus on potential users. A Living Lab can thus be defined as an innovation organization in which the whole value chain is involved in the development of innovative services in co-creation with users in a real world context (Ståhlbröst \& Bergvall-Kåreborn, 2011).

Living Lab research is emerging as a potentially important stream in innovation research. Until now, it has mainly been concerned with issues such as defining Living Labs (e.g. Feurstein et al., 2008; Følstad, 2008), explaining how Living Lab supports the innovation process (e.g. Schuurman et al., 2009), presenting the outcome of Living Lab projects (e.g. Mulder et al., 2008; Schaffers \& Kulkki, 2007) and suggesting how to effectively involve users in the Living Lab context (BergvallKåreborn \& Ståhlbröst, 2009).

For innovation professionals, Living Lab research can contribute to their innovation practices, since it offers an avenue to promote open service innovation. Despite this potential, Living Lab research has not yet been recognized as a legitimate approach in the innovation area. Moreover, Living Lab research lacks an agreed-upon theoretical basis (Bergvall-Kåreborn et al., 2009; Feurstein et al., 2008), and the aim of the research carried out in Living Labs is unclear. Therefore, this paper strives to raise awareness of the potential of Living Lab research and to increase its legitimacy in the innovation research area.

Criteria for conducting Living Lab research have not been widely debated or communicated. The focus of the discourse has mainly been to understand how Living Labs differ from traditional product development and open innovation and whether they make a unique and valued contribution (Almirall \& Wareham, 2008; Bergvall-Kåreborn et al., 2009; Dutilleul et al., 2010). However, what counts as Living Labs, how its operations could be conducted, and how the value of these operations can be assessed are areas that needs to be discussed among practitioners and researchers. 
Therefore, the purpose of this paper is two-fold: to propose a set of principles to support Living Lab research in an innovation context and to assess the impact of the Living Lab approach in an innovation process by means of the proposed principles. To achieve these goals, a service innovation project called SABER is examined. The characteristics of our Living Lab approach and its impact on the innovation process are clarified and discussed. The main motivation is to explain the basics of our approach to Living Lab research while being aware that the mission cannot be captured by a fixed set of principles once and for all. However, it should be possible to formulate a set of principles that captures some of the characteristics of Living Lab projects that have so far been reported.

Important to note here is that the proposed set of principles is merely one set that Living Lab researchers can choose to use. Given the diversity of Living Labs and the actions within these Living Labs, we caution against the principles being used as canons to limit the variety of actions that practitioners and researchers may conduct. Researchers are welcome to suggest other sets of principles. This is mainly a starting point for the development of Living Lab principles that can extend our understanding of the concept and its contribution to innovation research and practices. We also stress that the key principles described in this paper can be identified in other innovation processes carried out in other innovation contexts. Hence, we do not compare the efficiency and effectiveness of Living Lab innovation processes with other innovation processes; the goal is rather to describe a Living Lab process in which the identified key principles are reflected and assessed.

The remainder paper is organized as follows. The next section describes Living Labs and its key principles. Then, a project applying these principles is described followed by a discussion of their impact on the innovation process. The final section explores their contribution to, and impact on, the Living Lab approach.

\section{Living Labs and the Key Principles}

Within the area of Living Lab research, there exists no agreed upon definition of the concept. It has been defined as a methodology, an organization, a system, an arena, an environment, and/or a systemic innovation approach (Ballon et al., 2005; Dutilleul et al., 2010; Eriksson et al., 2005; Feurstein et al., 2008). Based on our interpretation of the concept as well as our practical experiences, we define Living Labs as both as an environment (milieu, arena) and an approach (methodology, innovation approach).

When viewed as an environment, many different types of Living Lab environments can exist: research Living Labs that might focus on performing research on different aspects of the innovation process, corporate Living Labs that focus on having a physical place where they invite other stakeholder (e.g. users) to co-create innovations, organizational Living Lab where the members of an organization co-creatively develop innovations, intermediary Living Labs where independent partners are invited to collaboratively innovate at a neutral arena, and Living Lab as a project, where the Lab exists during a project's lifetime to support the innovation process in that project and closes when the project ends. Due to constant development of the concept, other types also exist. This paper presents a study carried out in a research Living Lab with a focus on the operations carried out in the innovation process; hence, the Living Lab approach is in focus. 
The Living Lab approach is built on the five key principles which should permeate all Living Lab operations: value, sustainability, influence, realism and openness. The key principles reported here stem from a project called CoreLabs which examined existing Living Lab operations (Ståhlbröst, 2008). These principles reflect the multi-perspective that is often applied in Living Lab operations in order to reflect the complexity of the context in which the innovation will be implemented. Based on these principles, several cases carried out in two different Living Labs (Bergvall-Kåreborn et al., 2009) are analysed .

\subsubsection{Value}

In Living Labs, the goal is to create value for all stakeholders by having processes that emphasise this approach. This means that Living Lab processes support value creation in at least two different ways: for their partners (e.g. SMEs) in terms of business value and for the presumptive customer or user of the developed innovation in terms of user value. Business value is important for organisations to reach long-term prosperity and growth, which is of vital importance for their survival. Business value is a somewhat intangible term that includes all forms of value that determine the health and well-being of an organisation in the long-run. Business value includes aspects such as employee value, customer value, supplier value, managerial value and societal value. One way to mitigate competition and open up entirely new markets is by focusing on creating advances in customer value (Kim \& Mauborgne, 2005).

Providing a superior value for customers and users is a key aspect for business success (Boztepe, 2007; Cagan \& Vogel, 2002). Hence, organisations need to understand how to create value for their customers and strive to accomplish this goal. To be able to create value for customers and users, it is important to understand their needs and motivations as well as how these needs can be met by an innovation (Patnaik, 2004; Patnaik \& Becker, 1999). Focusing on customers' and users' needs gives organisations an opportunity to increase the level of innovation and to decrease the risk of developing something that customers do not want. Fulfilling a need by means of an innovation contributes to the creation of value for the customer. A value is usually defined as the experienced difference between benefits and sacrifices from using a service (Helander \& Ulkuniemi, 2012). The experienced value is influenced by the users' need for the service (direction) and how much a person wants something (intensity) (Scholer \& Higgins, 2009).

Living Lab processes support the process of understanding if the customer or user has a need for a service and how intense their attraction or repulsion for that service is in the real-world context. Users' experiences of the value of a service emerge when they use it (i.e. the use-value(Vargo et al., 2008). Vargo and Lusch (2006, p. 44) argue that "there is no value until an offering is used - experience and perception are essential to value determination." Living Labs can support processes by allowing users to elaborate with the service in their context to determine if it provides a value for them. In addition, a Living Lab can also provide insights about how users perceive value (Bergvall-Kåreborn \& Ståhlbröst, 2009). These insights can guide the innovation process to deliver innovations that are perceived as valuable from a business and a customer perspective. 
Title

\subsubsection{Sustainability}

Human life is dependent on a healthy and natural environment, which is rapidly degrading (Watson et al., 2010). It is therefore of utmost importance to work on a worldwide scale to create a sustainable environment for the future. Although the international determination to achieve environmental sustainability has been clearly articulated, considerable uncertainty remains at the individual, organizational, societal and governmental levels about problems and proposed solutions related to a sustainable environment (Elliot, 2011). Creating a sustainable environment includes economical, ecological and social aspects (SKR, 2004), which makes it a complex and multifaceted task. Sustainability can be defined as development that meets the need of the present without compromising the ability for future generations to meet their needs (Melville, 2010). Many organisations have potential to contribute to sustainable growth while improving productivity, lowering costs and strengthening revenue. The environmental activities taken today in many organisations are not adequate and can lead to different types of waste such as unused resources, inefficient energy use, and emissions which decrease energy efficiency (Watson et al., 2010).

This key principle refers both to the sustainability of the Living Lab and its responsibility to the wider community in which it operates. Focusing on the sustainability of the Living Lab highlights aspects such as continuous learning and development over time. Here, the research component of each Lab plays a vital role in transforming the generated knowledge from Living Lab operations into models, methods and theories. Also, in line with the general sustainability and environmental trends in society, it is equally important that Living Labs take responsibility for their ecological, social, and economic effects (Bergvall-Kåreborn \& Ståhlbröst, 2009). This means that the innovation processes supported by a Living Lab must address sustainability issues, for instance, by choosing the right materials, implementing environmentally-friendly processes, and considering the social and economical impact that the innovation might have once implemented. This principle is the least mature but perhaps the most important for creating a lively society now and in the future.

\subsubsection{Influence}

One key aspect of the influence principle is to view users as active, competent partners and domain experts. As such, their involvement and influence in innovation and development processes shaping society is essential. Equally important is to base these innovations on the needs and desires of potential users (Sleeswijk Visser et al., 2007) and to realise that these users often represent a heterogeneous group. This means utilising the creative power of Living Lab partners while facilitating their right to influence these innovations. By stressing the decision making power of potential users and domain experts, this principle differs from related concepts such as participation, involvement, and engagement which instead focus on the activities carried out by users and on users' psychological state (Barki \& Hartwick, 1989).

There are many reasons why users should be actively involved and have influence on innovation processes. Some of the most lucrative and novel innovations have been developed by users aiming to adapt existing product to fit their needs more 
appropriately (Di Gangi \& Wasko, 2009; Diga \& Kelleher, 2009; Vasalou et al., 2008; von Hippel, 2005). Involving more stakeholders in the innovation process can improve the quality of the service being developed (Praest Knudsen \& Bøtker Mortensen, 2011). Hence, many commercially attractive products that are at the forefront come from user innovations (Kaplan \& Haenlein, 2009; Nosko et al., 2009). In addition, the amount of ideas that users render as well as the heights of the innovative ideas are greater than those rendered by developers (Magnusson, 2003).

Users can also be involved and have influence on innovation processes for other reasons. For instance for democracy reasons since people have the right to have influence over things affecting them, or learning reasons because the innovation team might want to learn more about the users and/or want to educate the users, or economical reasons since knowing what the users want or need can make the innovation process more effective and efficient (Bergvall-Kåreborn \& Ståhlbröst, 2008). Adding to that is the emerging trend of customers and users who want the opportunity to influence products and services that they might use. For instance, Nike involves customers in developing and designing shoes; Threadless involves customers in T-shirt design; and Apple involves third-party developers to develop mobile apps for their platforms. The trend of letting customers and users influence companies' services can be expected to grow in the future.

One important issue that Living Labs need to manage is how to assure that participation, influence, and responsibility among different partners are balanced and harmonised with each other and with the ideology of the user influence of the project.

\subsubsection{Realism}

One of the cornerstones of the Living Lab approach is that innovation activities should be carried out in a realistic, natural, real-life setting. This is important, since people cannot experience anything independent of the experience they get from being embodied in the world (Yoo, 2010). In the users' real world context, they interact with other digital artefacts and social actors; they perform different actions and carry them out on different occasions. To increase understanding of how a digital artefact influences and fits into the actors' activities and goals, it is important to study them in their intended context. Yoo (2010, p. 218) explains: "Technology is not being interpreted, nor is it being experienced as an end in itself. Instead, it directly shapes and occasionally transforms our lived experiences." Orchestrating realistic use situation and understanding users' behaviour is one way to generate results that are valid for real markets in Living Lab operations (Ståhlbröst et al., 2009). However, the goal to create and facilitate realism needs to be addressed on different levels and in correlation to different elements such as contexts, users, use situations, technologies, and partners. This principle does not distinguish between physical and online contexts. Instead, it is argued that activities carried out in both contexts are real and realistic to actors. Inspired by online reality, we argue that IT based tools and methodologies can function as twin-world mediators (Attasiriluk et al., 2009) that facilitate the interconnection between real-world devices and their virtual counterparts.

When it comes to facilitating realistic use situations, two different approaches can be observed in relation to Living Labs. In the first approach, environments for testing and evaluating products or services are created in ways that are similar to 
the real world (Markopoulos \& Rauterberg, 2000), while in the second approach, products and services are tested and evaluated in users' real-world environments (Feurstein et al., 2008). Another important aspect related to the principle of realism, but not specifically addressed by the principle, is the fact that different stakeholders face different realities. This means that what is important and motivating for one stakeholder is not necessarily as important to another stakeholder. For example, a researcher's reality might be focused on producing scientific results, while an SME's reality might be to earn money by developing a new IT system. Consequently, it is crucial to involve users as well as other stakeholders in the development process. The reality aspect is also considered by involving real users rather than relying on personas or other user representative theories.

\subsubsection{Openness}

The current innovation landscape has changed. Many companies have thus identified a need to open up their innovation processes since innovation stakeholders have become more mobile, venture capital more abundant, and knowledge more widely dispersed across different types of organisations (van de Vrande et al., 2009). In the open innovation literature (e.g. Chesbrough, 2003, 2006; Chesbrough, 2011; Praest Knudsen \& Bøtker Mortensen, 2011), openness is concerned with opening up the innovation process with a flow of knowledge in two directions: inflow and outflow. Outflow of knowledge implies innovation activities that focus on leveraging existing technological capabilities outside the boundaries of the organisation. Inflow of knowledge relates to innovation activities that focus on capturing and benefiting from external sources of knowledge (Huizingh, 2011; van de Vrande et al., 2009). In Living Labs, the emphasis is on the inflow direction where several stakeholders are invited to participate in the innovation process.

The openness principle emphasises creating an innovation process that is as open as possible with the stakeholders. The idea is that multiple perspectives bring power to the development process and contribute to the achievement of rapid progress (Chesbrough, 2011). Openness is crucial for innovation processes in Living Labs due to efforts to gather a multitude of perspectives in order to develop as attractive an innovation as possible. Opening up innovation processes also offers potential to decrease the time to market and to better utilise collective creativity (van de Vrande et al., 2009). However, to be able to cooperate and share in a multistakeholder milieu, different levels of openness between stakeholders seems to be a requirement.

Chesbrough and Appleyard (2007) discuss whether openness is always beneficial. Bond et al. (2004) note that the reputational effectiveness of a company might be damaged by sharing too much information. Other researchers (e.g. Praest Knudsen \& Bøtker Mortensen, 2011) have found that open innovation might lead to worse timing to market and slower, more costly processes. Hence, more research is needed to define the values and challenges of open approaches.

Living Labs and similar innovation environments can strengthen innovation capacity due to cross-fertilization and open collaboration between different actors. The Living Lab may also provide an arena where different stakeholders can meet to support commercialisation and to bring products and services to market. 
Author

\section{The SABER Project}

The project being referred to in this paper is called SABER. During this project a product and a service concept aiming to support energy saving in buildings, was developed. The product and the service was also called SABER. The aim of the project was to implement the Living Lab approach in the development and innovation process. An additional goal was to increase the involved users' understanding of their energy consumption and hence make them aware of different ways to save energy at home. The project was conducted between 2008 and 2010 and was financed by Vinnova, a national innovation research founder in Sweden. Three main partners were involved: (1) the SME that owned the technology and was responsible for further development, (2) the Living Lab which was responsible for managing the project and the user involvement process as well as the Living Lab research related to it, and (3) voluntary private persons (i.e. users) who implemented and tested the technology in their homes and gave feedback on how the SABER concept could be developed to increase its usability and attractiveness as an energy-saving concept.

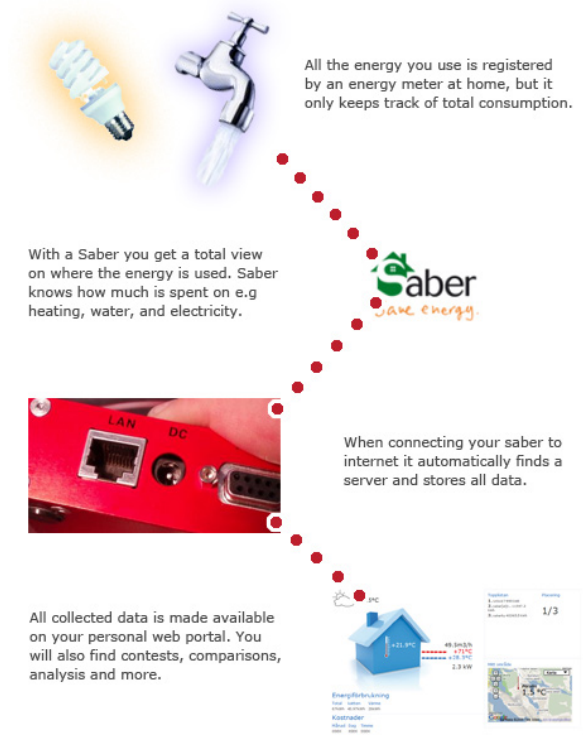

Figure 1: The Saber concept

The SABER concept combines measurement, visualisation and counselling. The measurement system is adapted to function in private households, companies and larger properties for metering electricity, district heating as well as both warm and cold water (see Figure 1). The SABER technology is connected to the building metering system and to the Internet so that the data can be sent to the SABER server. The software measures the consumption, and data for the individual meter is visualised to the user on a personal web portal as a service. In this portal, users have the opportunity to expand their data into different graphs, calculate their energy costs and compare their energy consumption between days, weeks and months on a 
Title

minute basis. Users can also compare their energy consumption with other households that have SABER installed. The aim of the SABER system is to provide users with the opportunity to reduce the energy consumption by visualizing realtime energy consumption.

\subsection{Methodology Applied in SABER}

In the SABER project, a Living Lab approach was applied and used to support the innovation and development process of the SABER concept as a whole. In this project, the focus was on development of a high fidelity prototype and of the final system. From an overarching perspective, the process of the project was designed to start with development of the SABER technology. This technology was a rather mature prototype that was close to market introduction but needed some development work to get the technology to function properly. In this process, we decided not to involve users since the focus was on the algorithm of the system, the circuit boards and the hardware for the system. Hence, our proposition was that the users, as private persons, had rather low interest and limited relevant understanding of the subject. The technology and the concept were tested with a limited number of users (n5) who discussed their experiences with installing and using it. The users' input was used and implemented in the re-design of the SABER concept. Next, the SABER was installed in several homes (n20) which tested it and gave feedback on their experiences and usage. In line with the Living Lab approach, we applied an iterative and interactive process in which users were actively involved throughout the development process.

We also wanted to extend our understanding of the Living Lab key principles and their role in the innovation process, so we consciously applied the key principles in the process. This meant that when implementing the openness principle, the Living Lab supported the SME to open up their innovation process and to increase the inflow of knowledge (Chesbrough, 2011) by inviting several stakeholders to participate in their innovation process. In this project, stakeholders such as presumptive customers, business developers, researchers and developers from other areas such as hardware developers were involved on different occasions. The influence principle was implemented by a conscious decision that the received input from the different stakeholders must be carefully considered and the results of their input should be communicated back to the users.

The value principle was implemented in two ways. First, the Living Lab approach strived to support the creation of a business value for the SME in the project by supporting them to develop their business based on the SABER concept. Second, the Living Lab approach supported the process of reaching an understanding of the intended customers needs and to investigate how the SABER system should be designed to create value for its end-users. This was accomplished through the usercentred interactive and iterative process that was applied in the project. In addition, the value principle was strengthened by its focus on creating value while the users actually used the technology, which is strongly related to the principle of realism. People cannot experience an innovation without knowing how it fits with their activities and other devices (Yoo, 2010). The realism principle was therefore achieved by the real-world implementation of the SABER system into the users' 
households. Hence, the technology was implemented and tested in the users' home environment.

Finally, the implementation of the sustainability principle was two-. Related to the process as a whole, the first goal was to minimise the environmental impact of development as much as possible. We therefore decided to use IT-technology to support the communication with the users instead of having them go to a meeting place. Reflecting the sustainability principle, the SABER system had the objective to lower energy consumption in buildings, which contributes to a sustainable environment from a societal perspective. All of these key principles were designed in the SABER project, and their application and impact were analysed.

\subsubsection{Prototype Development}

In the first phase of system development, the SABER technology was implemented in five private homes. The project participants interacted with these users during the process to gather their feedback concerning their experiences installing and using the SABER. In this phase, the focus was to improve the usability of the personal web portal and the installation instructions. To get aquatinted with the SABER, the users installed the system in their homes and used the technology for three weeks without any interaction from the project. To increase the users' ability to directly interact with each other and with the SME, and to have the opportunity to influence the innovation being developed, an online discussion forum was implemented. In this forum, the users discussed problems with the product, such as its installation and how they solved the Internet connection to the SABER since it often was installed in the boiler room. They also gave input on how the concept could be developed with additional functionalities such as scaling graphs and services such as suggestions where they could buy cheap energy. The users also highlighted problems experienced with the technology, such as the system losing contact with the server. They usually received help from the SME within a short period of time (one to two days).

In this phase, the focus was to gain an understanding of how the users understood and engaged the system. After three weeks, the users were somewhat familiar with the system, so we gave them tasks designed to support use while allowing the project team to ask usability questions. For instance, one task was for the user to read how much water they consumed on a specific date. The users were asked how easy it was to carry out this task and how important that specific functionality was in their everyday life. In this phase, a 7-point Likert scale was used where 1 indicated "I do not agree at all", and 7 indicated "I completely agree." The statements that were presented to users included "It was very easy for me to understand how to use the portal" and "The language on the portal was very easy for me to understand." After answering, users were invited to give suggestions on how to improve the SABER concept.

During this process, the users indicated that the functionality of the system was good and that the functions were relevant and interesting. They experienced some problems with the installation of the system and believed that the usability of the web portal could be improved. For instance, users said that the language at the portal was hard to understand. This was fixed by the SME, which added help functions and explanatory texts. The users also gave suggestions on how the SABER 
Title

system could be further developed to create added value. Examples of improvements include the ability to make their own graphs and to obtain more detailed information about their consumption. This was implemented by the SME by making it possible to transfer raw data to Excel. The five users suggested twelve new ideas, including more explanatory text on the portal and the ability to choose different scales of the graphs to compare with the outdoor temperature, which were also implemented.

In the SABER online discussion forum, which was designed in threads, the users discussed additional solutions and services to better meet their needs. The suggestions were related to how they could save energy based on their consumption and how to obtain information on where to buy energy at a low price. The users' input was taken seriously; the developers interacted with the users to answer their questions about the SABER system and to discuss the users' suggestions for improvement. Consequently, six of the suggested improvements were implemented.

\subsubsection{Development of the Final System}

After these changes had been implemented, the second cycle of the SABER project began. In this cycle, 20 users installed and used the SABER system and its related services for almost six months in their homes. The Living Lab interacted with the users through the discussion forum and phone calls; the latter was mainly used for questions to the SME. The SME and the Living Lab strived to build a close relationship with the users during this stage; hence, they encouraged the users to interact with them continuously in the discussion forum by asking questions, starting discussions and answering questions. In this way, it was possible to get the user's immediate reactions and experiences as they emerged. One issue was commitment among users. Not all users were engaged in the process and gave feedback.

To get a collective view of the users' experiences at the end of this phase, an online question form was distributed via e-mail. Fourteen users responded to the questionnaire. We also carried out qualitative phone interviews with twelve users. Questions regarded installation of the technology, usage, experiences, and the effect of the system on the users' energy consumption. Based on the survey responses and interviews, the added value of the SABER concept was identified as the control and understanding of energy consumption that the system provided. Some users decreased their energy consumption by approximately 10\%, which also had a monetary value. Users were encouraged to give some final suggestions on how the SABER concept could be improved to increase their willingness to adopt it in the future. This resulted in twelve suggestions for new functionalities in the system and eight suggestions on how the system could be improved. The SME implemented two new functions and two improvements based on the users' input. One implemented suggestion was that the system could send monthly graphs to the users, which was both a service for the users and a reminder of the SABER system. At the end of the project, a qualitative interview with the SME was conducted with the objective to understand how it perceived the Living Lab process. 
Author

\section{The Impact of the Living Lab Approach}

In order to succeed with innovations, the developed innovation must create value for its intended users (Helander \& Ulkuniemi, 2012). In our Living Lab process, value was created in two ways. The SME experienced the value of being involved in the Living Lab process since they for instance, did not have the resources to carry out these user interaction processes themselves. This created a value for the SME, which had the opportunity to both receive and provide information related to their product from and to their envisioned customers. This, in turn, gave the SME the increased possibility to develop the SABER concept, which created value for SME. Based on the stakeholders' input, he could re-design the concept by adding functionalities and modernising the web portal.

Taking part in Living Lab operations also made it possible for the SME to test the idea and get results from its usage. The Living Lab tests indicated that visualisation of energy consumption can lead to increased awareness of energy saving possibilities. This can give users incentive to decrease energy consumption in their homes. Hence, the positive results from the Living Lab operations could be used to create business with new presumptive customers for the SME. Testing the SABER concept in a real-world context also made it possible for the SME to identify bugs in the system and its installation that, according to the SME, would not have been possible to identify otherwise. Hence, the SME was able to carry out user involvement activities that they do not have the resources or knowledge to carry out themselves. Moreover, the user involvement activities carried out in the project provided feedback on the innovation that made it possible for the SME to do necessary re-designs that strengthened the value provided to customers. These aspects made it possible for the SME to further develop their business.

In Living Lab processes, it is also important to support sustainability, that is, the innovation process should support the development of sustainable innovations. The sustainability principle also implies that the innovation process as such should be sustainable. The sustainable process in this case was manifested by the project goal to reduce travel as much as possible in the project. Based on this, the partners mainly used IT tools to support their meetings and communication. This was also true for the user involvement activities, where tools such as online surveys, email, online discussion forums and phones were used to support the interaction. The innovation strived to contribute to a sustainable society by decreasing electricity, energy and fresh water consumption. In future Living Lab innovation processes, it would be beneficial to do research on how Living Lab approaches should be designed to really contribute to a sustainable society.

The third principle is influence. In the SABER project, several of the users' suggestions were implemented in the innovation and thus had influence. In this project, the influence was mainly related to the design and the service offering from the SME; for example, users wanted help choosing an inexpensive energy provider. The SME stated that they used the input to make changes in the SABER, which were communicated back to the users to make sure that they understood it correctly. In this process, the users had influence over the SABER concept, which in turn led to needed improvements of the software. 
One aspect to consider for the system developer is that not all suggestions from users are implementable or even required by the majority of users. The SME acknowledged this situation, stating that users' expressed needs provided direction rather than specific solutions; users do not always know what they need or want before the solution has entered the market. What is important here is that users believe their input is valued. Users involved in Living Lab activities needs to be treated with respect since they invest time to participate in the innovation process, often without any compensation for their efforts. In some cases, users' suggestions cannot be implemented at the current stage of the development process; this needs to be communicated back to the users to maintain their engagement in the process. For instance, several users stated that they wanted to control their outlets using their mobile phones. This was not possible to implement at the current stage but was communicated back to users as an interesting idea that the SME would consider. Involving the users in the development process also has dual benefits, as the SME expressed: "Involving users gives me an opportunity to both get and give information about my products and services."

Realism in this project meant that the Living Lab operations were carried out in a realistic setting with realistic problems and interferences. Through this approach, users could relate the system to their real energy consumption. According to their responses in the interviews, they experienced SABER as a very interesting concept. They stated that it increased their understanding of their energy consumption in ways that would not have been possible in a laboratory study. They also wanted to enrich the SABER concept to better support their needs related to energy consumption, for instance, by having more sensors in their home so that SABER could become central for the house as a whole. Hence, testing in real-life settings contributed to increased understanding of the innovation being tested. The users gave feedback on improvements based on their real-life experiences. The likelihood that they will adopt the innovation increased, since the system became a part of their everyday practice.

From the very beginning of the project, the SME opened up their process and invited other stakeholders, such as users and business developers, into the development. According to the SME, this led to increased insight into the users' situation, which made it possible for them to design the SABER system accordingly. This effort required an open mindset from the SME, which implemented some of the suggestions given by users. The value of opening up the process was expressed by the SME as follows: "We would not have any product or service if it was not for the users input, and we see the benefit of involving them as early as possible in the process to get suggestions on how to improve or further develop our concept."

In this project, the SME involved was in a vulnerable stage since the company had recently started up, which could mean increased risk by opening up their innovation process. The SME said that "the risk of opening up their process decreases if we open up as early as possible since we get to know the users' needs early on." Thus, opening up the process had a positive impact on the SMEs' product and service concept. Important to note here is that the SME really needs to consider which part of their development process they want to open up and how much they want to reveal of their business idea. 


\section{Author}

\section{Conclusions}

This paper provides a set of key principles which can guide the design and assessment of Living Lab studies. The principles are designed to help increase both the number of Living Lab articles and the depth of the dissemination with which Living Lab researchers understand their domain of investigation. This, in turn, will strengthen and enrich their contribution to the Living Lab research literature. Living Labs lie at the intersection between technology development, business development, and technology use. It is both an innovation and social construct that deals with ideation, analysis, constructs, deployment, use, evaluation, evaluation and management of innovation in every day contexts. Within this setting, Living Labs are proactive with respect to innovation. They focus on creating and evaluating innovations that enable people to carry out their efforts more efficiently and effectively.

The assessment of the Living Lab approach using the key principles showed an impact on the innovation process and the stakeholders. For instance, the Living Lab approach created business values for the involved SME and value for the intended customers through improved design of the innovation. By implementing a Living lab approach, a channel to the surrounding context was opened for the SME which gave many new ideas about how they could improve their offerings in ways that would not have been possible otherwise. The suggested ideas from the users were also taken seriously and had an actual impact on the design of the innovation. Implementing the innovation in the users' real world context also brought value to the users through, for instance, increased understanding and knowledge about how they could save energy. Having sustainability in focus also impacted the innovation process, which used IT tools that made it possible for users to give situated input on the innovation.

The advances made in this paper aim to stimulate further reflection and debate on the importance of Living Lab research and how its quality can be improved and assessed.

\section{Acknowledgement}

The author of this paper would like to thank the contributors to this research, the users, the SMEs and all colleagues at Botnia Living Lab. This work was funded by the SABER project sponsored by Vinnova, the Open Innovation and Living Labs project also sponsored by Vinnova, the projects SociaLL and SmartIES sponsored by Nordforsk and the EU-funded project called APOLLON.

\section{References}

Aas, T. H. and Pedersen, P. E. (2010). The Firm-Level Effects of Service Innovation:: A Literature Review. International Journal of Innovation Management, Vol. 14, No. 5, pp.759-794.

Almirall, E. and Wareham, J. (2008). Living Labs and Open Innovation: Roles and Applicability. The Electronic Journal for Virtual Organisations and Networks, Vol. 10, No. Special Issue on Living Labs, pp.22-46. 
Title

Attasiriluk, S. A., Nakasone, A., Hantanong, W., Prada, R., Kanongchaiyos, P. and Prendinger, H. (2009). Co-Presence, Collaboration, and Control in Environmental Studies a Second Life-Based Approach. Virtual Reality, Vol. 13, No. 3, pp.195-204.

Ballon, P., Pierson, J. and Delaere, S., (2005). Open Innovation Platforms for Broadband Services: Benchmarking European Practices. Paper read at 16th European Regional Conference, at Porto, Portugal, 177,

Barki, H. and Hartwick, J. (1989). Rethinking the Concept of User Involvement. MIS Quarterly, Vol. March, No., pp.52-63.

Bergvall-Kåreborn, B., Ihlström Eriksson, C., Ståhlbröst, A. and Svensson, J. (2009). A Milieu for Innovation - Defining Living Labs. The 2nd ISPIM Innovation Symposium - Stimulating Recovery - The Role of Innovation Management, New York City, USA., 6-9 December 2009

Bergvall-Kåreborn, B. and Ståhlbröst, A., (2008). Participatory Design - One Step Back or Two Steps Forward. Paper read at PDC 2008 Experiences and Challenges, at Bloomington, Indiana, USA, 473, Simonsen, J.Robertson, T. and Hakken, D. pp.102-111

Bergvall-Kåreborn, B. and Ståhlbröst, A. (2009). Living Lab - an Open and CitizenCentric Approach for Innovation. International Journal of Innovation and Regional Development, Vol. 1, No. 4, pp.356-370.

Bitner, M., J, Ostrom, A., L and Morgan, F., N. (2008). Service Blueprinting: A Practical Technique for Service Innovation. California Management Review, Vol. 50, No. 3, pp.66-94.

Bond E, U., Walker, B., A, Hutt, M., D and Reingen, P. H. (2004). Reputational Effectiveness in Cross-Functional Working Relationships. Journal of Product Innovation Management, Vol. 21, No. 1, pp.44-60.

Boztepe, S. (2007). User Value: Competing Theories and Models. International Journal of Design, Vol. 1, No. 2, pp.55-63.

Cagan, J. and Vogel, C. M. (2002). Creating Breakthrough Products: Innovation from Product Planning to Program Approval. Upper Saddle River, NJ: Prentice Hall.

Chesbrough, H. (2003). The Era of Open Innovation. MIT Sloan Management Review, Vol. 44, No. 3, pp.35-42.

Chesbrough, H. (2006). Open Innovation; a New Paradigm for Understanding Industrial Innovation. In Open Innovation: Researching a New Paradigm, edited by Chesbrough, H.Vanhaverbeke, W. and West, J. Oxford: Oxford University Press.

Chesbrough, H. (2011). Open Service Innovation - Rethinking Your Business to Grow and Compete in a New Era. San Fransisco: Jossey-Bass.

Chesbrough, H. and Appleyard, M. (2007). Open Innovation and Strategy. California Management Review, Vol. 50, No. 1, pp.57-76.

Di Gangi, P. M. and Wasko, M. (2009). Steal My Idea! Organizational Adoption of User Innovations from a User Innovation Community: A Case Study of Dell Ideastorm. Decision Support Systems, Vol. 48, No. 1, pp.303-312.

Diga, M. and Kelleher, T. (2009). Social Media Use, Perceptions of Decision-Making Power, and Public Relations Roles. Public Relations Review, Vol. 35, No. 4, pp.440-442. 
Author

Dutilleul, B., Birrer, F. A. J. and Mensink, W. H. (2010). Unpacking European Living Labs: Analyzing Innovation's Social Dimensions. Central European Journal of Public Policy, Vol. 4, No. 1, pp.60-85.

Elliot, S. (2011). Transdisciplinary Perspectives on Environmental Sustainability: A Resource Base and Framework for It-Enabled Business Transformation. MIS Quarterly, Vol. 35, No. 1, pp.197-A13.

Eriksson, M., Niitamo, V. P. and Kulkki, S. (2005). State-of-the-Art in Utilizing Living Labs Approach to User-Centric Ict Innovation - a European Approach. Centre of Distance Spanning Technology at Luleå University of Technology, Sweden, Nokia Oy, Centre for Knowledge and Innovation Research at Helsinki School of Economics, Finland.

Feurstein, K., Hesmer, A., Hribernik, K. A., Thoben, T. D. and Schumacher, J. (2008). Living Labs: A New Development Strategy. In European Living Labs - a New Approach for Human Centric Regional Innovation, edited by Schumacher, J. and Niitamo, V. P. Berlin: Wissenschaftlicher.

Følstad, A. (2008). Living Labs for Innovation and Development of Information and Communication Technology: A Literature Review. The Electronic Journal for Virtual Organisations and Networks, Vol. 10 No. Special Issue on Living Labs,, pp.100-131.

Helander, N. and Ulkuniemi, P. (2012). Customer Percieved Value in the Software Business. Journal of HIgh Technology Management Research, Vol. 23, No., pp.26-35.

Huizingh, K. R. E. (2011). Open Innovation: State of the Art and Future Perspectives. Technovation, Vol. 21, No., pp.2-9.

Kaplan, A. M. and Haenlein, M. (2009). The Fairyland of Second Life: Virtual Social Worlds and How to Use Them. Business Horizons, Vol. 52, No. 6, pp.563-572.

Kim, W. C. and Mauborgne, R. A. (2005). Blue Ocean Strategy: From Theory to Practice. California Management Review, Vol. 47, No. 3, pp.105-121.

Magnusson, P. (2003). Customer-Oriented Product Development - Experiments Involving Users in Service Innovation. doctoral thesis, Stockholm: Economic Research Institute, Stockholm: School of Economics, Stockholm.

Markopoulos, P. and Rauterberg, G. W. M. (2000). Livinglab: A White Paper.

Melville, N. (2010). Information Systems Innovation for Environmental Sustainability. MIS Quarterly, Vol. 34, No. 1, pp.1-21.

Mulder, I., Bohle, W., Boshomane, S., Morris, C., Tempelmann, H. and Velthausz, D. (2008). Real-World Innovation in Rural South Africa. The Electronic Journal for Virtual Organisations and Networks, Vol. 10, No. Special Issue on Living Labs, pp.7-20.

Nosko, A., Wood, E. and Molema, S. (2009). All About Me: Disclosure in Online Social Networking Profiles: The Case of Facebook. Computers in Human Behavior, Vol. In Press, Corrected Proof, No.

Patnaik, D. (2004). System Logics: Organizing Your Offerings to Solve People'S Big Needs. Design Management Review, Vol. Summer 2004, No., pp.50-57.

Patnaik, D. and Becker, R. (1999). Needfinding: The Why and How of Uncovering People's Needs. Design Management Journal, Vol. 10, No. 2, pp.35-43.

Praest Knudsen, M. and Bøtker Mortensen, T. (2011). Some Immediate - but Negative - Effects of Openness on Prodeuct Development Performance. Technovation, Vol. 31, No., pp.54-64. 
Title

Rai, A. and Sambamurthy, V. (2006). Editorial Notes--the Growth of Interest in Services Management: Opportunities for Information Systems Scholars. In Information Systems Research: INFORMS: Institute for Operations Research.

Schaffers, H. and Kulkki, S. (2007). Living Labs: A Strategy for Open Innovation Fostering Rural Development. Asia-Pacific Tech Monitor, Special Issue on Open Innovation: A New Paradigm in Innovation Management, Vol., No. September-October 2007.

Scholer, A. A. and Higgins, E. T. (2009). Exploring the Complexities of Value Creation: The Role of Engagement Strength. Journal of Consumer Psychology, Vol. 19, No. 2, pp.137-143.

Schuurman, D., Evens, T. and Marez, L. D. (2009). A Living Lab Research Approach for Mobile Tv. Proceedings of the seventh european conference on European interactive television conference, Leuven, Belgium,

Shelton, R. (2009). Integrating Product and Service Innovation. Research Technology Management, Vol. 52, No. 3, pp.38-44.

SKR. (2004). En Svensk Strategi För Hållbar Utveckling - Ekonomisk, Social Och Miljömässig.

Sleeswijk Visser, F., van der Lugt, R. and Stappers, P. J. (2007). Sharing User Experiences in the Product Innovation Process: Participatory Design Needs Participatory Communication. Creativity and Innovation Management, Vol. 16, No. 1, pp.35-45.

Ståhlbröst, A. (2008). Forming Future It - the Living Lab Way of User Involvement, Department of Business Administration and Social Sciences, Luleå University of Technology, Luleå.

Ståhlbröst, A. and Bergvall-Kåreborn, B. (2011). Exploring Users Motivation in Innovation Communities. International Journal of Entrepreneurship and Innovation Management, Vol. 14, No. 4, pp.298-314.

Ståhlbröst, A., Holst, M., Bergvall-Kåreborn, B. and Sällström, A., (2009). Striving for Realism in a User-Involvement Process. Paper read at 2nd ISPIM Innovation Symposium - Stimulating Recovery - The Role of Innovation Management, at New York City, USA., 553,

van de Vrande, V., de Jong, J., Vanhaverbeke, W. and de Rochemont, M. (2009). Open Innovation in Smes: Trends, Motives and Management Challenges. Technovation, Vol. 29, No., pp.423-437.

Vargo, S. L. and Lusch, R. (2006). Service-Dominant Logic: What It Is, What It Is Not, Wha Tit Might Be. In The Service-Dominant Logic of Marketing: Dialog, Debate and Directions, edited by Lusch, R. and Vargo, S. L. Armonk: M.E. Sharpe Inc.

Vargo, S. L., Maglio, P. P. and Akaka, M. A. (2008). On Value and Value Co-Creation: A Service Systems and Service Logic Perspective. European Management Journal, Vol. 26, No. 3, pp.145-152.

Vasalou, A., Joinson, A., Bänziger, T., Goldie, P. and Pitt, J. (2008). Avatars in Social Media: Balancing Accuracy, Playfulness and Embodied Messages. International Journal of Human-Computer Studies, Vol. 66, No. 11, pp.801811.

von Hippel, E. (2005). Democratizing Innovation. Cambridge, Massachusetts: The MIT Press. 
Author

Watson, R., Boudreau, M.-C. and Chen, A. (2010). Information Systems and Environmentally Sustainable Development: Energy Informatics and New Directions for the Is Community. MIS Quarterly, Vol. 34, No. 1, pp.23-28.

Williams, K., Chatterjee, S. and Rossi, M. (2008). Design of Emerging Digital Services: A Taxonomy. European Journal of Information Systems, Vol. 17, No., pp.505517.

Wooder, S. and Baker, S. (2012). Extracting Key Lessons in Service Innovation. Journal of Product and Innovation Management, Vol. 29, No. 1, pp.13-20.

Yoo, Y. (2010). Computing in Everyday Life: A Call for Research on Experiental Computing. MIS Quarterly, Vol. 34, No. 2, pp.213-231. 